\title{
Comparative Study of Early Versus Delayed Enteral Feeding in Development of Necrotizing Enterocolitis for Preterm Small for Date Babies
}

\author{
PIYABISWAS ${ }^{1}$, JUGINDRA SINGHA ${ }^{2}$, MUJIBUL HOQUE² ${ }^{2}$, MD. MONIR HOSSAIN ${ }^{3}$, MANAJJIR ALI ${ }^{4}$
}

\begin{abstract}
:
Background: Growth-restricted preterm infants are at increased risk of developing necrotizing enterocolitis (NEC) and initiation of enteral feeding is frequently delayed, even though delayed enteral feeding could diminish the functional adaptation of the gastrointestinal tract and result in feeding intolerance later. Objectives: To evaluate the development of necrotizing enterocolitis of early and delayed enteral feeding in preterm small for date babies (weighing 1000-1499 grams).

Materials and Methods: This was a consecutive sampling technique, conducted in the Department of Paediatrics Sylhet MAG Osmani Medical College Hospital during the period from July 2012 to June 2014. One hundred and forty neonates with preterm small for date babies were selected according to inclusion and exclusion criteria. Inclusion criteria were baby born preterm ( $<37$ completed weeks) having birth weight below $10^{\text {th }}$ percentile for gestational age, birth weight 1000- 1499 grams (VLBW), less than 48 hours postnatal age. Exclusion criteria were major congenital anomaly, Rhesus iso-immunization and Multiorgan dysfunction. They were divided randomly into two groups as Group A (early feeding group) and Group B (late feeding group) each consisting of 70 patients. After randomization 10 patients from group-A and 5 patients from group- $B$ were excluded from analysis due to incomplete data. So, final sample size was 60 patients in Group A and 65 patients in Group B.
\end{abstract}

Results: Gestational age (34.27 \pm 1.07 weeks vs $33.97 \pm 1.30$ weeks; $p=0.167$ ), sex (41 male, 19 female vs 40 male, 25 female; $p=0.427$ ) and weight (1196. \pm 135.9 gram vs $1172.3 \pm 136.4$ gram; $p=0.288$ ) were statistically similar in early and late feeding group. Development of necrotizing enterocolitis [4 (6.7\%) vs 5 (7.7\%); $p=1.000$ ] and sepsis [3 (5.0\%) vs 5 (7.7\%); $p=0.719$ ] did not differ between early and late feeding group. Final outcome such as discharged home [45 (75.0\%) vs 47 (72.3\%); $p>0.05$ ], death [10 (16.7\%) vs 11 (16.9\%); $p>0.05]$, oral feeding not established [1 (1.7\%) vs 2 (3.1\%); $p>0.05]$, referred to paediatric surgery [4 (6.7\%) vs $5(7.7 \%) ; p>0.05]$ did not differ significantly between early and late feeding group. Causes of death were sepsis in $3(30.0 \%)$, recurrent apnoea in $4(40.0 \%)$ ] and hypothermia in $3(30.0 \%)$ in early feeding group; while causes of death were sepsis in 5 (45.5\%), recurrent apnoea in 4 $(36.4 \%)]$ and hypothermia in $2(18.1 \%)$ neonates in late feeding group ( $p=0.861, p=0.881, p=0.781$ respectively).

Conclusion: Findings of this consecutive sampling technique concludes that early enteral feeding with breast milk does not increase the incidence of NEC, sepsis and death.

Key Words: Necrotizing enterocolitis, Early Feeding, Late feeding, Preterm Small for Date Babies.

1. Assistant Professor, Department of Paediatrics, Park View Medical College, Sylhet.

2. Associate Professor, Department of Paediatrics, MAG Osmani Medical College, Sylhet.

3. Assistant Professor, Department of Neonatology, MAG Osmani Medical College, Sylhet.

4. Ex-Professor and Head, Department of Paediatrics, MAG Osmani Medical College, Sylhet.

Correspondence: Dr. Piya Biswas, Assistant Professor Department of Paediatrics, Park View Medical College, Sylhet. Received: 217 April, 2017
Accepted: 31 May 2017
Introduction:

Low birth weight is one of the major health problems both in developed and developing countries and is closely associated with fetal and neonatal mortality and morbidity, inhibited growth and poor cognitive development of children, increased risk of chronic diseases later in life. ${ }^{1}$

The global prevalence of LBW is $15.5 \%$ which means that every year about 20.6 million such infants are 
born each year with $96.5 \%$ of them in developing countries. There is significant variation in LBW incidence rate across the world with the highest incidence in south central Asia (27.1\%) and lowest in Europe $(6.5 \%))^{2,3}$ There is no actual data of VLBW and preterm small for date babies in our country. Prevalence of LBW in Bangladesh is $21.6 \%{ }^{4}$ Approximately one third of low birth weight infants are small for date babies. ${ }^{5}$ It can be assumed that about $7 \%$ babies are born small for date in Bangladesh. Due to good obstetric care and day by day improvement of neonatal care survival of preterm infants increases. Feeding strategy is one of the major clinical challenges, because of excess prematurity, Very low birth weight preterm infants are not often able to be directly breast fed and prolonged parenteral nutrition will predispose them to sepsis and phlebitis. ${ }^{6}$

Observational studies suggest that when prematurity is further complicated by intrauterine growth restriction (IUGR), the incidence of necrotizing enterocolitis (NEC) is even higher. IUGR caused by placental insufficiency is characterized by blood flow redistribution to the vital organs (brain, myocardium, and adrenal glands), while other organs, including the gastrointestinal tract, are deprived from sufficient blood flow. ${ }^{7-10}$ As a consequence of gut ischemia/hypoxia, IUGR infants are thought to have impaired gut function after birth, which may result in intestinal disturbances, ranging from temporary intolerance of enteral feeding to full-blown NEC. $7,8,9,11$

Although the exact etiology and pathogenesis of NEC remains elusive, it is well established that NEC is a complex, multi-factorial disease. Besides pre-maturity, research suggests that other potential predisposing factors are hypoxic-ischemic injury, feeding with formula milk and colonization by pathological bacteria. Previously it was thought that enteral feeds have a firm association with NEC as $90 \%-95 \%$ of NEC cases occur in infants with initiation/reinitiation of enteral feeds or recent volume advancement. Infants receiving hyperosmolar formulas or rapid volume advancements are at greatest risk. Although the mechanism is not well understood, enteral feeding has been reported to contribute to the development of NEC through disruption of mucosal integrity, blood flow and motility and through provision of a bacterial substrate. Rapid rise of milk intake increases metabolic demands, making it difficult for the infant to expand mesenteric blood flow to meet demands. As a result, intestinal hypoxemia may occur. Increased proliferation of potentially pathogenic bacteria unabated to invade the bowel wall. ${ }^{12}$ It is thought that as enteral feeding may increase the risk of NEC in preterm IUGR infants, its initiation is often postponed. However, such a policy exposes infants to the risks of prolonged parenteral nutrition, delayed establishment of oral feeding, and prolonged duration of intensive care and hospital stay. ${ }^{10}$

The optimum time for introducing enteral feeding to a VLBW infant is controversial. Trophic feeding is the practice of feeding to very low birth weight premature infants to stimulate development of immature gastrointestinal tract. The benefits of trophic feeding include enhanced gut motility, improved growth, decreased need for parenteral nutrition, fewer episodes of sepsis and shortened hospital stay. Once the infant is stable, small volume feeding are given in addition to intravenous fluid. Feeding is graduallyadvanced and parenteral nutrition decreased. Careful early feeding of breast milk or formula tends to reduce the risk of hypoglycemia, dehydration, and hyperbilirubinemia. ${ }^{13}$

Most infants weighing $<1500 \mathrm{gm}$ require tube feeding because they are unable to coordinate breathing, sucking and swallowing. Intestinal tract readiness for feeding maybe determined by active bowel sound, passage of meconium, and the absence of abdominal distention, bilious gastric aspirate. Enteral feeding can begin as early as day 1 (provided infant is medically stable). Using small volume trophic feed (approximately $10 \mathrm{ml} / \mathrm{kg} / \mathrm{day}$ ) to stimulate gastrointestinal tract and prevent mucosal atrophy.As baby can tolerate feeding may be increased by $10-$ $20 \mathrm{ml} / \mathrm{kg} /$ day. Clinical studies across the world have consistently demonstrated that infants who are fed earlier and are advanced according to a feeding plan achieve full enteral feeds sooner than their counterpart. Although the fear of precipitating NEC remains widespread, randomized controlled trials have repeatedly failed to show any relationship between feeding practices and the occurrence of NEC. ${ }^{14}$ 
In this respect, minimal enteral feeding (MEF) of very low-birth-weight infants has been introduced as a strategy to improve feeding tolerance and prevent complications of prolonged parenteral nutrition. ${ }^{10}$ Although MEF has been shown to improve the clinical outcome with no additional increase in the relative risk of any complication, limited information is currently available regarding the effect of early versus delayed introduction of MEF on feeding intolerance or NEC outcomes in IUGR infants. ${ }^{17}$ Additionally, most trials of enteral feeding in preterm infants have showed conflicting results. ${ }^{17,18}$ Thus, the feeding protocol that would be more suitable for preterm infants with IUGR. ${ }^{10}$ not yet standardized. Early introduction of enteral feeds may improve nutrition and growth and better outcome but may increase the risk of NEC. ${ }^{25}$ Conversely late introduction may results in villous atrophy and reduced hormone and enzyme production due to lack of intestinal stimulation. ${ }^{6}$ Late introduction may also results in prolonged use of parenteral nutrition with increased risk of sepsis,cholestatic jaundice and vitamin and mineral deficiencies. ${ }^{7}$ One study suggested that early enteral feeding is better than delayed enteral feeding for preterm small for date babies. ${ }^{20}$ There was no evidence of a difference in the incidence of NEC in both groups.

In the absence of accepted standards for feeding preterm infants with IUGR, the present study aimed to examine the effect of early versus delayed introduction of enteral feeding on the incidence of NEC in preterm small for date babies.

\section{Methods:}

This was a consecutive sampling technique, Conducted in the Department of Paediatrics Sylhet MAG Osmani Medical College Hospital during the period from July 2012 to June 2014. One hundred forty neonates with preterm small for date babies were selected according to inclusion and exclusion criteria. Inclusion criteria were baby born preterm $(<37$ completed weeks) having birth weight below $10^{\text {th }}$ percentile for gestational age, birth weight 1000-1499 grams (VLBW), less than 48 hours postnatal age. Exclusion criteria were major congenital anomaly, Rhesus iso-immunization, previous intrauterine or exchange transfusion and multiorgan dysfunction. They were divided randomly into two groups as Group A (early feeding group) and Group B (late feeding group) each consisting 70 patients. After randomization 10 patients from group-A and 5 patients from group-B were excluded from analysis due to incomplete data. So, final sample size was 60 patients in Group A and 65 patients in Group B.

\section{Randomization and intervention:}

Detail history of all neonate admitted in paediatrics ward weighing 1000-1499 gm were taken. Then thorough examination were done of these neonates.

Gestational age was calculated from LMP (Last menstrual period) and NBS (New Ballard score). When there is discrepancy between LMP and NBS, then NBS was considered final. When gestational age was less than 37 weeks and birth weight below $10^{\text {th }}$ percentile then these babies were included in the study.

After enrollment group allocation of the first case was done by lottery method. First case was selected for early feeding group and second case went to other group (delayed feeding group). Then group allocation continued accordingly.

Trophic feeding or gut priming $(1 \mathrm{ml} / \mathrm{kg})$ was the minimum amount of feeding to prepare gut. After 4 hours of first feeding, if no intolerance of feeding developed then second feeding was given as same amount for one day.

After a trophic feeding of $1 \mathrm{ml} / \mathrm{kg}$, the feeds were gradually increased in both groups. Amount of increment of feeds were same in both groups e.g-2 $\mathrm{ml} 2$ hourly on day 3 , increased $4 \mathrm{ml} 2$ hourly on next day and so on to reach $150 \mathrm{ml} / \mathrm{kg} /$ day and sustained for 72 hours. The only difference in both groups were the day of starting of feeds- early groups on day 2 and delayed group on day 4 .

NG tube was introduced and a syringe was connected with the open end of tube to administered feeds, and milk was administered by the law of gravitation. To measure the gastric tube length, the tube tip was at the xiphisternum and measured to the ear lobe and then to the nose. Infants in each group received $1 \mathrm{ml} /$ $\mathrm{kg}$ breast milk every 4 hours on day 1 and were advanced $2 \mathrm{ml} / \mathrm{kg} /$ day if tolerated along with parenteral nutrition. Parenteral nutrition was started just after admission and continued until milk feeding 
established. The only choice was the mother's breast milk. Feeding was started in 2 days of birth in early feeding group and 4 days in delayed feeding group. Rate of increase of feed was same for both groups. Follow up was given every day to monitor vital signs, tolerance of feeding, vomiting, urine output, bowel movement, abdominal distention, any bleeding manifestation. The target was to reach $150 \mathrm{ml} / \mathrm{kg} /$ day and sustain for 72 hours.

If feeding intolerance developed which was manifested by inability to digest enteral feeding and presented as prefeed GRV (gastric residual volume) more than $50 \%$, abdominal distention, vomiting or both then enteral feeding was stop in affected infant. Perenteral nutrition was continued along with stoppage of enteral feeding for 2 days. After 2 days if there was no or minimum gastric aspirate, no vomiting or subsidence of abdominal distention again trophic feeding was started and increased gradually.

But if still infants cannot tolerate feeding then they were considered as early stage of NEC and treatment was given for NEC accordingly along with keeping infant nothing per oral. If any infant developed sepsis then he or she was treated accordingly. Treatment modalities for both groups were according to management plan of preterm small for date babies in Sylhet MAG Osmani Medical College Hospital. In everyday follow up, along with vital signs, tolerances of feeding, development of NEC in both early and delayed group were observed. NEC wasdiagnosed by clinical criteria, plain X-ray abdomen and CBC. NEC was diagnosed clinically in any infant presenting with the triad of feeding intolerance, abdominal distension, and grossly bloody stool. NEC was categories according to the modified bell's classification.

\section{Bell's staging criteria:}

Stage-I: (Suspect) clinical signs symptoms, including abdominal signs and no diagnostic radiograph

Stage-II: (definite) clinical signs and symptoms, pneumatosis intestinalis portal venous gas on radiograph.

Stage-III: (Advanced) clinical signs and symptoms, pneumatosis intestinalis on radiograph and critically ill.

\section{Flow chart: Randomization and intervention}

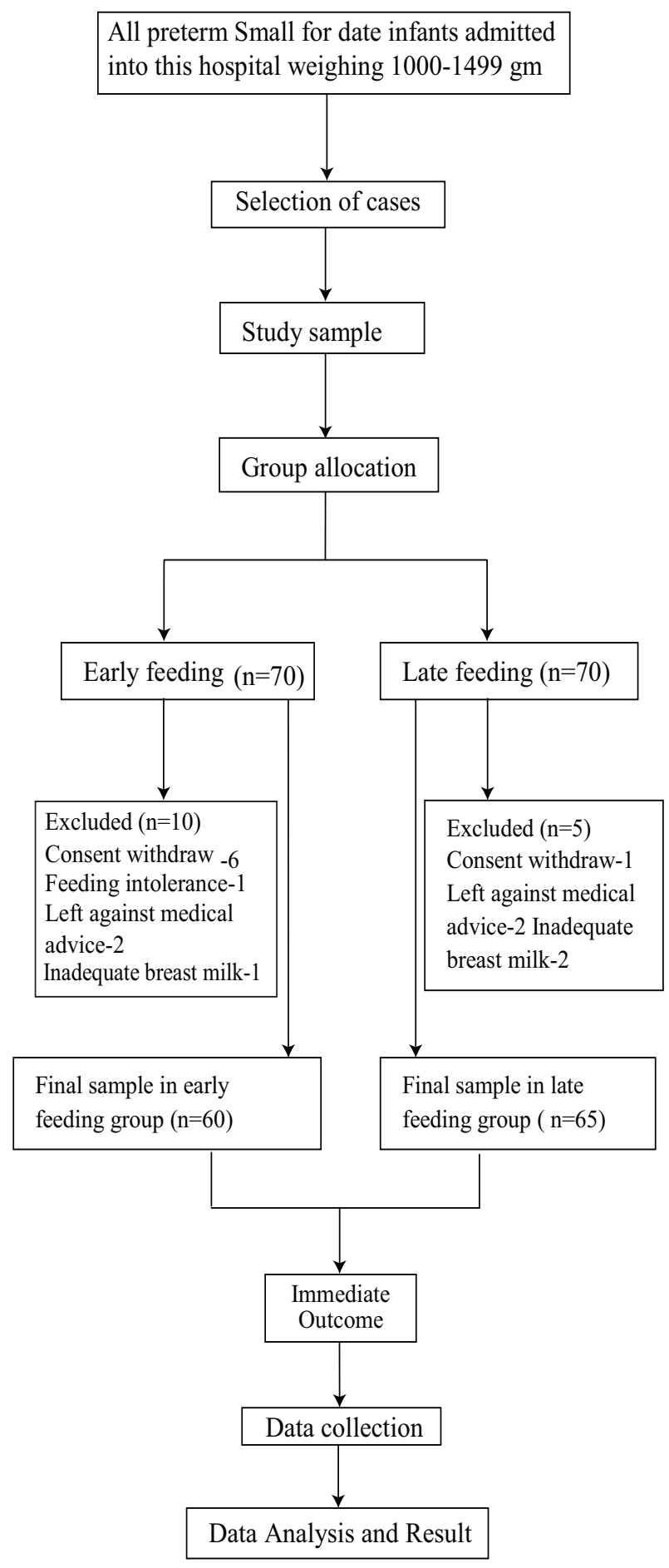

\section{Data collection and analysis}

Relevant data were recorded in a pre-designed data collection sheet designed for the study. Data were processed manually and analyzed with the help of SPSS (Statistical package for social sciences) Version 21.0. 
Quantitative data were expressed as mean and standard deviation; and comparison was done by unpaired " $\mathrm{t}$ " test.

Qualitative data was expressed as frequency and percentage and comparison was carried by Chi-square $\left(\chi^{2}\right)$ test or Fisher's exact test.

A probability value $(p)$ of less than 0.05 was considered statistical significance.

\section{Ethical consideration}

Informed written consent was taken from legal guardian of each patient before taking any interview. The consent form clearly described the purpose and methods of the study, confidentiality of the interviews, risks and benefits of participating in the study, their rights to participate voluntarily and to refuse at any point in time without consequences.

The protocol was approved by the institutional ethical committee of Sylhet MAG Medical College, Sylhet before the commencement of the study.

\section{Observation and Results}

Table-I

Distribution of the patients on baseline characteristics

\begin{tabular}{lccc}
\hline $\begin{array}{l}\text { Baseline } \\
\text { characteristics }\end{array}$ & $\begin{array}{c}\text { Study subjects } \\
\text { Early } \\
\text { feeding } \\
(\mathrm{n}=60)\end{array}$ & $\begin{array}{c}\mathrm{p} \text { - } \\
\text { feedayed } \\
(\mathrm{n}=65)\end{array}$ & value \\
\hline $\begin{array}{l}\text { Gestational age } \\
\quad 52-33 \text { weeks }\end{array}$ & $5(8.3)$ & $14(21.5)$ & $\mathrm{p}=0.118$ \\
$\quad 34-35$ weeks & $42(70.0)$ & $38(58.5)$ & \\
$\quad 36$ weeks & $13(21.7)$ & $13(20.0)$ & \\
$\quad$ Mean \pm SD in & 34.27 & 33.97 & $\mathrm{p}=0.167$ \\
$\quad$ weeks & \pm 1.07 & \pm 1.30 & \\
Mode of delivery & & & \\
$\quad$ Vaginal delivery & $46(76.7)$ & $45(69.2)$ & $\mathrm{p}=0.351$ \\
$\quad$ Caesarean section $14(23.3)$ & $20(30.8)$ & \\
Sex & & & \\
$\quad$ Male & $41(68.3)$ & $40(61.5)$ & $\mathrm{p}=0.427$ \\
$\quad$ Female & $19(31.7)$ & $25(38.5)$ & \\
Weight (mean $\pm S D)$ & 1196.3 & 1172.3 & $\mathrm{p}=0.288$ \\
gms & \pm 135.9 & \pm 136.4 & \\
\hline
\end{tabular}

The mean gestational age in both groups was almost identical (34.27 \pm 1.07 weeks vs $33.97 \pm 1$.30 weeks; $t=1.390 ; p=0.167$ ). Gestational age was also similar when gestational age was categorized in weeks $\left(\chi^{2}=4.270 ; p=0.118\right)$.

Mode of delivery between groups did not differ significantly $\left(\chi^{2}=0.871 ; p=0.351\right)$.

The sex of the patients in group-A and group-B did not Show any statistically significant difference $\left(\chi^{2}=0.632 ; p=0.427\right)$.

The mean weight of the patients in both groups did not differ significantly $(1196.3 \pm 135.9$ gram vs. 1172.3 \pm 136.4 gram; $t=1.068 . p=0.288$ ).

\section{Table-II}

Distribution of patients according to development of NEC.

\begin{tabular}{|c|c|c|c|}
\hline \multirow{2}{*}{$\begin{array}{l}\text { Development } \\
\text { of NEC }\end{array}$} & \multicolumn{2}{|c|}{ Study subjects } & \multirow{2}{*}{$\begin{array}{c}p-p \\
\text { value }\end{array}$} \\
\hline & $\begin{array}{l}\text { Early } \\
\text { feeding } \\
(n=60)\end{array}$ & $\begin{array}{c}\text { Delayed } \\
\text { feeding } \\
(n=65)\end{array}$ & \\
\hline Yes 4 (6.7) & $5(7.7)$ & $p=1.000$ & \\
\hline No 56 (93.3) & $60(92.3)$ & & \\
\hline
\end{tabular}

Necrotizing enterocolitis (NEC) developed in 4 (6.7\%) neonates in early feeding group and $5(7.7 \%)$ neonates in late feeding group. Difference between two feeding groups was not statistically significant $(p=1.000)$.

Table-III

Distribution of patients according to development of sepsis

\begin{tabular}{|c|c|c|c|}
\hline \multirow{3}{*}{$\begin{array}{l}\text { Development } \\
\text { of sepsis }\end{array}$} & \multicolumn{2}{|c|}{ Study subjects } & \multirow{3}{*}{$\begin{array}{c}p- \\
\text { value }\end{array}$} \\
\hline & Early & Delayed & \\
\hline & $\begin{array}{l}\text { Feeding } \\
(n=60)\end{array}$ & $\begin{array}{l}\text { Feeding } \\
(n=65)\end{array}$ & \\
\hline Yes & $3(5.0)$ & $5(7.7)$ & $p=0.719$ \\
\hline No & $57(95.0)$ & $60(92.3)$ & \\
\hline
\end{tabular}

Sepsis developed in $3(5.0 \%)$ neonates in early feeding group and $5(7.7 \%)$ neonates in late feeding group. Difference between two feeding groups was not statistically significant $(p=1.000)$. 
Table-VI

Distribution of patients according to Immediate outcome

\begin{tabular}{|c|c|c|c|}
\hline \multirow{2}{*}{$\begin{array}{l}\text { Final } \\
\text { outcome }\end{array}$} & \multicolumn{2}{|c|}{ Study subjects } & \multirow{2}{*}{$\begin{array}{c}\mathrm{p}- \\
\text { value }\end{array}$} \\
\hline & $\begin{array}{c}\text { Early } \\
\text { feeding } \\
(n=60)\end{array}$ & $\begin{array}{c}\text { Delayed } \\
\text { feeding } \\
(n=65)\end{array}$ & \\
\hline Discharged & $45(75.0)$ & $47(72.3)$ & $p>0.05$ \\
\hline Death & $10(16.7)$ & $11(16.9)$ & $p>0.05$ \\
\hline $\begin{array}{l}\text { Feeding not } \\
\text { established }\end{array}$ & $1(1.7)$ & $2(3.1)$ & $p>0.05$ \\
\hline $\begin{array}{l}\text { Referred to paediatric } \\
\text { surgery }\end{array}$ & $4(6.7)$ & $5(7.7)$ & $p>0.05$ \\
\hline
\end{tabular}

Final outcome such as discharged from hospital [45 $(75.0 \%)$ vs 47 (72.3\%); $Z=0.343 ; p>0.05]$, death [10 $(16.7 \%)$ vs $11(16.9 \%) ; Z=-0.030 ; p>0.05]$, oral feeding not established [1 (1.7\%) vs $2(3.1 \%) ; Z=-0.515$; $\mathrm{p}>0.05]$, referred to paediatric surgery [4 $(6.7 \%)$ vs 5 $(7.7 \%) ; Z=-0.216 ; p>0.05]$ did not differ significantly between early feeding group and late feeding group.

\section{Table-V}

Distribution of patients according to cause of death

\begin{tabular}{|c|c|c|c|}
\hline \multirow{2}{*}{$\begin{array}{l}\text { Cause of } \\
\text { death }\end{array}$} & \multicolumn{2}{|c|}{ Study subjects } & \multirow{2}{*}{$\begin{array}{l}p- \\
\text { value }\end{array}$} \\
\hline & $\begin{array}{c}\text { Early } \\
\text { feeding } \\
(n=10)\end{array}$ & $\begin{array}{c}\text { Delayed } \\
\text { feeding } \\
(n=11)\end{array}$ & \\
\hline Sepsis & $3(30.0)$ & $5(45.5)$ & $p=0.861$ \\
\hline Recurrent apnoea & $4(40.0)$ & $4(36.4)$ & $p=0.881$ \\
\hline Hypothermia & $3(30.0)$ & $2(18.1)$ & $p=0.781$ \\
\hline
\end{tabular}

Causes of death were sepsis in $3(30.0 \%)$, recurrent apnoea in $4(40.0 \%)$ ] and hypothermia in $3(30.0 \%)$ in early feeding group; while causes of death were sepsis in $5(45.5 \%)$, recurrent apnoea in $4(36.4 \%)$ ] and hypothermia in $2(18.1 \%)$ neonates in late feeding group. Difference between two feeding groups was not statistically significant $(p=0.861)$.

\section{Discussion}

Optimal enteral feeding methods in preterm infants have not been well defined. Controversy exists regarding when feeding should be started, whether minimal enteral feeding should be used routinely in small preterm infants, and how fast to advance enteral feedings. ${ }^{20}$ As NEC mostly occur after infants have received enteral feeds, it has become common practice to delay the start of enteral feeding in those considered to be at highest risk. ${ }^{6}$ Evidence suggests that very low birth weight infants who develop necrotizing enterocolitis have more gastric residuals than those who do not. ${ }^{21}$ In this study the mean gestational age in both groups was almost identical (34.27 \pm 1.07 weeks vs $33.97 \pm 1.30$ weeks; $p=0.167$ ). The mode of delivery between groups did not differ significantly in the current study $(p=0.351)$ (Table-I). These results was similar to the study of Sallakh-Niknezhad et al. ${ }^{20}$

In the present study the sex of the patients in early enetral feeding and late enetral feeding did not show any statistically significant difference $(p=0.427)$ (Table I). This result was correlated with the study of Leaf et al. ${ }^{6}$ that the sex of the infants in early enetral feeding and late enetral feeding did not show any statistically significant difference. But there was a significant difference of sex of the infants between early enetral feeding and late enetral feeding group in the study of Sallakh-Niknezhad et al. ${ }^{20}$

In this study the mean weight of the patients in both groups did not differ significantly $(1196.3 \pm 135.9$ gram vs $1172.3 \pm 136.4$ gram; $p=0.288$ ) (Table-I). This result was supported by Leaf et al. ${ }^{6}$ and Sallakh-Niknezhad et al. $^{20}$ that there was no significant difference of weight of the infants between early enetral feeding and late enetral feeding group.

The most common reason for delayed initiation and limited advancement of enteral feeds in immature infants is concern about increasing the risk of NEC. The present study showed that the frequency of necrotizing enterocolitis (NEC) was fewer in early feeding group than that of late feeding group but difference between two feeding groups was not statistically significant (Table-II). This result was correlated with the study of Leaf et al. ${ }^{6}$ that there was no difference was found in the incidence of NEC, particularly for serious Bell's stage 2 or 3 . Result of a systematic review by Dorling et al. also consistent with the findings of the present study. ${ }^{16}$ The study by Karagianni et al. ${ }^{9}$ and van Elberg et al. ${ }^{17}$ investigated early versus late introduction of "trophic feeding" in SFD preterm infants and neither study revealed a difference in incidence of NEC.

A recent Cochrane review concluded that delaying the onset of enteral nutrition did not reduce the incidence of NEC. ${ }^{21}$ Additionally, infants on slow advancement 
strategies require long-term nutritional support in the form of parenteral nutrition. It is need to note that the participants in our study initiated feeds on day 2 and the unavailability of breast milk may have played a role when feeds were commenced in the first 24 hours. Randomised controlled trials as well as the Cochrane meta-analysis suggest that rapid advancement of feeds in increments of between $30-35 \mathrm{ml} / \mathrm{kg} / \mathrm{d}$ is safe with no increase in the risk of NEC. ${ }^{22,23,24}$ The meta-analysis of Tyson and Kennedy, ${ }^{25}$ in 692 infants, NEC rates are similar at $10.5 \%$ for MEF (minimal enteral feeding ) and $9.4 \%$ for control (parenteral nutrition) infants (relative risk $1.07,95 \% \mathrm{Cl} 0.84$ to 1.36), which is not significant. Further studies with adequate sample sizes are needed. If trophic feeding is shown to be safe with regard to NEC, substantial savings from reduced length of stay, use of parenteral nutrition, and episodes of septicaemia should be reduced. Frequency of development of sepsis was fewer in early feeding group than that of late feeding group but difference between two feeding groups was not statistically significant (Tabl-III). This result was consistent with study of Leaf et al. ${ }^{6}$ that there was no statistically significant difference in the development of late onset sepsis between the early feeding group and late feeding group. This result was correlated with the study of Sallakh-Niknezhad et al. ${ }^{19}$ that there was no statistically significant difference in the development of sepsis between early and late feeding group.

In this study discharged of neonate from hospital did not differ significantly between early group and late feeding group (Table-IV). This result was supported by the study of Leaf et al. ${ }^{6}$ that discharged from the hospital in both early and late feeding group was almost similar.

In this study death from all cause was almost similar in both early feeding and late feeding group but none of these death were due to gastrointestinal causes (Table-V). Similar findings were reported in the study of Leaf et al. ${ }^{6}$ A meta-analysis also did not detect any statistically significant differences overall death (typical RR 1.06 (95\% Cl 0.55 to 2.05). ${ }^{26}$

On the other hand, others studies showed that delaying enteral feeding could be detrimental. Parenteral nutrition is usually used as an alternative source of nutrients, but side effects are common ${ }^{12}$ (Sepsis, Pulmonary embolism, metabolic complication, Cholestatic liver disease etc). In this respect, MEF (minimal enteral feeding) of very low- birth-weight infants has been introduced into clinical practice as an alternative approach to delayed enteral feeding. ${ }^{9}$ This approach has recognized benefits, including enhanced endocrine and exocrine hormonal activity, improved growth of intestinal mucosa, maturation of gut motility, and improved overall clinical outcome, with no proven increase in the relative risk of feeding intolerance or NEC. $25,26,27$

\section{Limitations of the study}

- Single centre study

- Small sample size.

- No NICU facility in this hospital.

\section{Conclusion}

There was no increase in the incidence of NEC, Sepsis and death with early enternal feeding in comparison to delayed enternal feeding in preterm small for date babies in this study.

\section{Recommendation}

- A large multicenter study can be conducted to confirm the findings of the present study.

\section{References}

1. Carlo WA. Prematurity and Intrauterine growth restriction. In: Kligman RM, Stanton BF, Geme ST, Behrman RE. Nelson Textbook of pediatrics. $19^{\text {th }}$ ed. New Delhi: Elsevier; 2011. p. 550-558.

2. Gomella T L. Neonatology. Management Procedures on Call Problems, Diseases and Drugs. $5^{\text {th }}$ ed. India: McGraw Hill Companies; 2006.

3. Patole SK, Klerk N. Impact of standardized feeding regimens on incidence of neonatal necrotizing enterocolitis. A systematic review and meta-analysis of observational studies. Arch Dis Child Fetal Neonatal 2005;90:147-151.

4. Yasmin S, Azim, E. Status of low birth weight at a tertiary level hospital in Bangladesh for a selected period of time. South East Asia J Pub Health 2011;1:24-27.

5. OECD/WHO. Low birth weight in health at a glance: Asia/Pacific 2012, OECD Publishing, 2012. Available from: http://dx.doi.org/10.1787/ 9789264183902-17-en. Accessed on: 19 January 2014.

6. Lee KG. Identifying the high risk new born and evaluating gestational age, prematurity, post maturity, large-for-gestational age and small- for- 
gestational age infants. In: Cloherty JP, Eichenwald EC, Stark AR, editors. Manual of Neonatal Care. $6^{\text {th }}$ eds. New Dehi: Wolters Kluwer/ Lippincott Williams and Wilkins; p.4156.

7. Leaf A, Dorling J, Kempley S, McCormick K, Mannix P, Linsell L, et al. Abnormal Doppler Enteral Prescription Trial Collaborative Group. Early or delayed enteral feeding for preterm growth-restricted infants: a randomized trial. Pediatrics 2012, 129:e1260-1268.

8. Gilbert WM, Danielsen B. Pregnancy outcomes associated with intrauterine growth restriction. Am J Obstet Gynecol 2003;188:1596-1599.

9. Bhatt AB, Tank PD, Barmade KB, Damania KR. Abnormal Doppler flow velocimetry in the growth restricted foetus as a predictor for necrotisingenterocolitis. J Postgrad Med 2002;48:182-185.

10. Karagianni P, Briana DD, Mitsiakos G, Elias A, Theodoridis T, Chatziioannidis E, et al. Early versus delayed minimal enteral feeding and risk for necrotizing enterocolitis in preterm growthrestricted infants with abnormal antenatal Doppler results. Am J Perinatol 2010;27:367-373.

11. Manogura AC, Turan O, Kush ML, Berg C, Bhide A, Turan S, et al. Predictors of necrotizing enterocolitis in preterm growth-restricted neonates. Am J Obstet Gynecol 2008; 198: 638e1-638e5.

12. Schnabl KL, Van Aerde JE, Thomson AB, Clandinin MT Necrotizing enterocolitis: a multifactorial diseasewith no cure. World J Gastroenterol 2008;14(14):2142-2161

13. Mallaiah R. Nutrition in low birth weight infant. Quarterly Medical Review 2007; 58 (4): 2-4.

14. Gartner LM, Morton J, Lawrence RA, Naylor AJ, O'Hare D, Schanler RJ, et al. Breastfeeding and the use of human milk. Pediatrics 2005;115:496506.

15. Meinzen-Derr J, Poindexter B, Wrage L, Morrow $A L$, Stoll B, Donovan EF. Role of human milk in extremely low birth weight infants' risk of necrotizing enterocolitis or death. J Perinatol 2009;29:57-62

16. Walker DM, Marlow N. Neurocognitive outcome following fetal growth restriction. Arch Dis Child Fetal Neonatal Ed 2008;93(4):322-325.
17. Dorling J, Kempley S, Leaf A. Feeding growth restricted preterm infants with abnormal antenatal Doppler results. Arch Dis Child Fetal Neonatal Ed 2005; 90: F359-F363.

18. van Elburg RM, van den Berg $A$, Bunkers $C M$, van Lingen RA, Smink EW, van Eyck J, et al. Minimal enteral feeding, fetal blood flow pulsatility, and postnatal intestinal permeability in preterm infants with intrauterine growth retardation. Arch Dis Child Fetal Neonatal Ed 2004;89:F293-F296.

19. Lauin JE, Cousens S, Zupan J. Four million neonatal deaths: When? Where? Why? Lancet 2005; 365: 891-900.

20. Sallakh-Niknezhad A, Bashar-Hashemi B, Satarzadehr N, Ghoiazadeh M, Sahnazarli G. Early versus late trophic feeding in very low birth weight preterm infants. Iranian J Pediatr 2012;22 (2):171-176.

21. Cobb BA, Carlo WA, Ambalavanan N. Gastric residuals and their relationship to necrotizing enterocolitis in very low birth weight infants. Pediatrics 2004;113:50-53.

22. Morgan J, Young L, McGuire W. Delayed introduction of progressive enteral feeds to prevent necrotisingenterocolitis in very low birth weight infants. Cochrane Database Syst Rev 2011;3:CD001970

23. Morgan J, Bombell S, McGuire W. Early trophic feeding versus enteral fasting for very preterm or very low birth weight infants. Cochrane Database Syst Rev 2013: (3): CD000504.

24. Krishnamurthy S, Gupta P, Debnath S, Gomber $S$. Slow versus rapid enteral feeding advancement in preterm newborn infants 1000 1499g: a randomized controlled trial. Acta Paediatr 2010;99:42-46

25. Tyson JE, Kennedy KA. Trophic feedings for parenterally fed infants. Cochrane Database Syst Rev 2005; (3): CD000504.

26. Arnon S, Sulam D, Konikoff F, Regev RH, Litmanovitz I, Naftali T. Very early feeding in stable small for gestational age preterm infants: a randomized clinical trial. J Pediatr (Rio J) 2013;89(4):388-393.

27. Hartung J, Kalache KD, Heyna C, Heling KS, Kuhlig M, Wauer R, et al. Outcome of 60 neonates who had ARED ûow prenatally compared with a matched control group of appropriate-for-gestational age preterm neonates. Ultrasound Obstet Gynecol 2005;25:566-572 